\title{
Implicações e problematizações do conceito de Intersubjetividade: um enfoque na formação do profissional de línguas
}

\author{
Implications and problematizing of the concept \\ of Intersubjectivity: a focus on the education of \\ language professionals
}

\author{
Mary Elizabeth Cerutti-Rizzatti* \\ Universidade Federal de Santa Catarina \\ Florianópolis, Santa Catarina / Brasil. \\ Adriana Kuerten Dellagnelo** \\ Universidade Federal de Santa Catarina \\ Florianópolis, Santa Catarina / Brasil.
}

\begin{abstract}
RESUMO: Este artigo tematiza o conceito de intersubjetividade, com base em Wertsch (1985), com enfoque na formação do profissional de línguas. Constitui uma abordagem que parte da seguinte questão-problema e procura responder a ela: Que relaçôes é possivel estabelecer entre: (i) o que avaliamos como um paulatino amadurecimento no dominio teórico visivel nas enunciaçôes orais e escritas de acadêmicos sob nossa orientação e (ii) o estreitamento das relaçôes correspondentes a essa mesma orientação institucionalizada entre nós e eles? Para tanto, apresenta o mencionado conceito de intersubjetidade, problematiza-o, propondo sua ressignificação com base no conceito de encontro do filósofo italiano Augusto Ponzio, e analisa, em uma abordagem interpretativista (MASON, 1996), dados de diário de campo correspondentes a um grupo de pesquisa na área da linguagem, tendo como escopo tal proposta de ressignificação. Os resultados apontam para uma concepção de que a gradação - de que trata o autor norteamericano na tessitura do conceito - implica a condição de encontro para se consolidar. Desse processo decorre, neste caso específico, a autonomia de acadêmicos no tratamento de questôes teórico-epistemológicas da área do conhecimento em tela.
\end{abstract}

PALAVRAS-CHAVE: intersubjetividade; formação docente; encontro.

\footnotetext{
*ma.rizzatti@gmail.com

**adrianak@cce.ufsc.br
} 


\begin{abstract}
In view of Wertsch's (1985) concept of intersubjectivity, this article focuses on the education of language professionals and develops around the following research question: Which relations can be established between: (i) what we call a gradual theoretical maturation of students under our supervision as seen in their oral and written enunciations and (ii) the development of closer relations corresponding to this institutionalized supervision between them and us? To answer this issue, we introduce the concept of intersubjectivity, question it, and propose its resignification on the basis of the concept of encontro by the Italian philosopher Augusto Ponzio. An interpretive approach (MASON, 1996) is used to analyze data from field journals corresponding to a language research group. Results suggest that the gradation involved in the concept of intersubjectivity, as proposed by the American scholar, implies the condition of encontro in order to consolidate. In this context, this process triggers students' autonomy in relation to the theoretical-epistemological issues of the present area of scientific knowledge.
\end{abstract}

KEYWORDS: intersubjetivity; teacher education; encontro.

\title{
1 Introdução
}

Este artigo tem como objeto a formação de profissionais na área da educação em linguagem, âmbito em que problematizamos o conceito de intersubjetividade tal qual proposto por Wertsch (1985), na busca de compreendê-lo na convergência com o conceito de encontro que emerge da obra do filosófio italiano Augusto Ponzio quando de sua vinculação ao ideário bakhtiniano. O tratamento desse tema, como se dá no corpo do artigo, implica ressignificação de ambos os conceitos aqui em foco intersubjetividade e encontro, em uma discussão cujo objetivo é trazer novos elementos para as reflexões sobre formação de profissional em línguas no campo dos programas de pós-graduação nessa área.

$\mathrm{O}$ artigo subdivide-se em três seções de conteúdo: na primeira delas, apresentamos o conceito de intersubjetividade com base em Wertsch (1985); na seção seguinte, propomos sua ressignificação a partir da articulação com o conceito de encontro; na terceira e última, à luz da proposta de ressignificação levada a termo ao longo do artigo, discutimos dados de campo correspondentes a um grupo de pesquisa na área da linguagem, os quais foram gerados por meio de notas em diário de orientação.

\section{Uma discussão inicial sobre o conceito de intersubjetividade}

Um olhar de base histórico-cultural para o ensino e a aprendizagem, em línguas ou em qualquer outra área do conhecimento, remete a discussões 
sobre a natureza social das funções psíquicas superiores, questão de que se ocupou Vygotsky ${ }^{1}$ (2015 [1931]). Sob a ótica vigotskiana, há indissociabilidade entre a atividade dos sujeitos - externas ou internas - e a atividade social em que tais sujeitos se engajam. Nessa indissociabilidade tem lugar uma dinâmica de internalização em que processos interpsíquicos convertem-se em processos intrapsíquicos. Wertsch (1985) dedicou-se ao estudo acerca das implicações dessa dinâmica de transformação do interpsíquico para o intrapisquismo. Escreve esse autor:

[...] in the transition from interpsychological to intrapsychological functioning, any change in the former involves a corresponding change in the latter. It is sometimes assumed that there is a sudden, clean shift from social to individual functioning - a child works with someone on a task and then begins to carry it out independently. But to characterize the transition in this way is to miss the main point about its dynamic, namely, that a series of changes typically occurs on the interpsychological plane and that each is reflected in a change in intrapsychological functioning. Of course, these changes are not always in the form of quantitative increments; many are qualitative. (WERTSCH, 1985, p. 159)

Para o autor norte-americano, importa haver um estudo mais acurado acerca de como tal processo de internalização acontece a partir das relações interpsíquicas, o que entendemos relevante considerando que essa dinâmica se institui a partir do universo de objetivações humanas que se colocam para cada sujeito singular pela mediação de outros sujeitos. Essa mediação, quando em processos educativos, foco de interesse deste artigo, remetenos ao conceito de intersubjetividade proposto por Wertsch (1985), que apresentamos brevemente, tanto quanto o problematizamos, nesta seção.

Com o conceito de definição de situação, o autor norte-americano focaliza implicações semióticas da transformação do funcionamento interpsíquico para o funcionamento intrapsíquico. Trata-se de uma perspectiva que considera que os sujeitos em interlocução colaborativa negociam sentidos, implicados na situação de comunicação, acerca do objeto ou evento nela relevante; quando tais sentidos passam a operar de modo semelhante isso lhes faculta usos abreviados da linguagem ${ }^{2}$, em uma atividade de natureza

\footnotetext{
${ }^{1}$ Ao longo deste artigo, grafaremos o nome do autor de acordo com a forma com que as traduções das obras consultadas para este artigo o fizerem.

${ }^{2}$ Importa considerar que quanto maior o domínio dos sujeitos sobre os sentidos implicados na situação de comunicação, mais sucinta e abreviada é a sua linguagem.
} 
semiótica que incide sobre a zona de desenvolvimento iminente ${ }^{3}$, que é produto da intersubjetividade. Escreve o autor:

When interlocutors such as an adult and a child in the zone of proximal development approach a setting with dissimilar situation definitions, it may at first be difficult to see how they could carry on effective communication. After all, they represent many aspects of the setting in quite different ways. To understand this apparent problem, one needs to invoke the notion of intersubjetivity. Intersubjectivity exists when interlocutors share some aspect of their situation definitions. Typically this overlap may occur at several levels, and hence several levels of intersubjectivity may exist. (WERTSCH, 1985, p. 159)

Sob essa perspectiva, a intersubjetividade institui uma atividade colaborativa entre os sujeitos, sendo focalizada pelo autor sob a ótica de uma gradação. Nessa discussão, Wertsch (1985) reporta estudos de Ragnar Rommetveit para quem diferentes gradações na intersubjetividade resultam da atividade de natureza semiótica que tem lugar nas relações sociais, nas quais - e em razão das quais - os sujeitos envolvidos transcendem seus mundos privados, naquilo que é compreendido como estados de intersubjetividade. Nas palavras de Wertsch (1985, p. 161):

[...] when interlocutors enter into a communicative context, they may have different perspectives or only a vague interpretation of what is taken for granted and what the utterances are intended to convey. Through semiotically mediated "negotiation," however, they create a temporarily shared social world, a state of intersubjectivity.

Em se tratando de tal gradação, em estudos em que o autor teve como base a análise microgenética de relaçōes entre mãe e filho (crianças entre dois e quatro anos de idade), com foco no desenvolvimento de mecanismos

${ }^{3}$ Optamos por iminente e não por imediata - que vínhamos usando a partir de justificativas de Bezerra (2001) - nem por proximal - da qual nos afastamos exatamente em razão da mencionada justificativa de Bezerra (2001), e o fazemos a partir de Martins (2011) e de Prestes (2010), autoras segundo as quais iminente representa termo mais coerente com a sistematização teórica que sustenta o conceito, tendo presente que a característica essencial são as possibilidades de desenvolvimento da criança, possibilidades que podem se consolidar, estando na dependência das relações que estabelece com o interlocutor mais experiente; não se trataria, pois, nem de proximidade, nem de imediatez. 
semióticos usados pelos adultos na atividade colaborativa, identificou quatro níveis de transição do funcionamento interpsíquico para o funcionamento intrapsíquico (WERTSCH, 1985²). O primeiro nível se caracterizaria por uma substantiva distinção naquilo que define a situação, processo em que a interlocução entre os sujeitos caracteriza-se como difícil. Em um segundo nível as aproximações na definição da situação já seriam maiores, mas as diferenças ainda inviabilizam inferências implicadas nos sentidos em negociação. "This level is generally characterized by the fact that the child is beginning to participate successfully in the task setting, but the child's understanding of the task situation is still far from being in complete agreement with the adult's." (WERTSCH, 1985, p. 163). Já em um terceiro nível, a criança tenderia a responder apropriadamente às regulações do adulto, fazendo as inferências necessárias para interpretar as orientações do outro quando elas não se explicitam verbalmente. "While the process is still carried out on the interpsychological plane, the fact that the child can make the appropriate inferences indicates that intrapsychological functioning is beginning to account for much of the child's performance." (p. 163). Enfim, no quarto e último nível, a criança assumiria total responsabilidade pela realização da atividade, e a fala egocêntrica emergiria durante ou logo após a transformação para o funcionamento intrapsíquico e, nessa forma de autorregulação da mediação semiótica, se explicitariam propriedades estruturais e funcionais que caracterizariam a interlocução precedente em que a heteronomia ou heterorregulação predominava. Para Wertsch $(1985,164)$, "At this point there is almost complete intersubjectivity between adult and child on the situation definition, a fact that makes further other-regulation unnecessary."

No entendimento do autor, assim, a zona de desenvolvimento iminente seria o lócus semiótico em que tem lugar o processo de transformação do funcionamento interpsíquico para o funcionamento intrapsiquico, considerando que, na intersubjetividade, os sujeitos em mediação semiótica desenvolvem uma atividade em que se dá a regulação de uns sobre os outros. Tendo presente os níveis propostos por Wertsch (1985), haveria um movimento progressivo de heterorregulação ou heteronomia para a

\footnotetext{
${ }^{4}$ Nesta obra, James Wertsch retoma obra sua de 1979: Wertsch, J. V. (1979a) From social interaction to higher psychological processes: A clarification and application of Vygotsky's theory. Human Development 22 (I): 1-22.
} 
autorregulação ou autonomia passível de mapeamento em quatro níveis distintos. Escreve o autor:

While forms of interpsychological and intrapsychological functioning differ significantly, there seems to be at least one common tendency in how children in these studies come to master the situation definition of the task: they first participate in the execution of the goal-directed task on the interpsychological plane, and only subsequently do they recognize and master the strategic significance of their behaviors. Rather than understanding the task and then doing it, the children seem to have done the task (as a participant in interpsychological functioning) and then understood it. (WERTSCH, 1985, p. 166)

A esse respeito, aludimos ao entendimento de Wertsch (1998, p. 132) de que "performance precede competência", em cujo sentido está a compreensão de que, na zona de desenvolvimento iminente, há certo grau de intersubjetividade, porém isso não implica que essa intersubjetividade já seja marcada por intencionalidade e agência.

Essas proposições de Wertsch (1985) interessam-nos, aqui, por uma razão específica: vimos tomando, em nossos estudos, o conceito de intersubjetividade sob outros contornos, que explicitaremos na próxima seção, e essa (re)tomada dos estudos desse autor americano nos faz atentar para a compreensão de que a intersubjetividade, quando em articulação com o ideário vigotskiano, não pode ser concebida sob um enfoque monolítico, requerendo atenção ao movimento dialético implicado na base do pensamento do autor russo e que está, assim, também no escopo da dinâmica que caracteriza as relaçôes entre o funcionamento interspsíquico e o funcionamento intrapsíquico.

Nessa (re)tomada, porém, da compreensão de Wertsch (1985) para intersubjetividade em que pese a dimensão dialética do pensamento vigotskiano, que implica a contradição -, inquieta-nos uma questão para a qual já atentaram autores como Smolka, Goés e Pinto (1998) no que se refere

\footnotetext{
${ }^{5}$ Distinguimo-nos, nesta menção, das noções de competência e performance tal qual tais conceitos são tomados em Lyotard (1979), o que remete a paradigmas objeto de crítica, como registrado em Duarte (2004). Quanto a essa citação, ainda, trata-se de consideração de Cazden (1981), revozeada por Wertsch (1998); o conteúdo dela nos interessa não com o acento que lhe é dado na fonte de origem, mas sob a ótica do tom do revozeamento.
} 
a uma eventual assepsia do olhar de Wetsch (1985) relativamente ao conflito, ao que é caótico na interlocução, ou ainda, como registram Bezerra e Meira (2006, p. 205), no que respeita ao dissenso que a intersubjetividade implicaria com o ideário vigotskiano "[...] segundo o qual o objeto da internalização não é o ponto de vista do outro, mas a dinâmica e os processos desenvolvidos nas relações." Em convergência com essa ressalva, Newman e Holzman (2002) entendem que Wertsch (1985) não atentou para conexões entre pensamento, ação e construção de sentidos, caras para o ideário vigotskiano, atendo-se, na compreensão de intersubjetividade que apresenta, a dimensões semióticas e discursivas. Já para Duarte (2001, p. 125), “[...] nas interaçōes entre sujeitos, isto é, nas interações intersubjetivas, não se trata de compartilhar significados, mas sim de supor, a partir de ações, que os significados sejam semelhantes, pelo fato de 'funcionarem' da mesma forma em várias situações [...]". Logo, a dimensão linguística, como instrumento da interlocução, é capital na discussão da intersubjetividade, mas a essência do conceito é a dinâmica por meio da qual se dá o movimento do plano interpsicológico para o plano intrapsicológico que viabiliza a apropriação da cultura.

A discussão que empreendemos, aqui, sobre intersubjetividade nos é cara porque entendemos que a educação escolar - para as finalidades deste artigo, no que respeita ao ensino e à aprendizagem de línguas -, quando tomada à luz do ideário vigotskiano, implica a formação de comportamentos complexos, já que o trabalho em educação atua na natureza social das funções psíquicas superiores. Assim considerando, a intersubjetividade tem lugar nodal nesta discussão, tendo presente que não são todas as atividades que redundam na aprendizagem que promove o desenvolvimento psíquico. Desse modo, importa que o delineamento das proposiçóes feitas aos alunos nos processos de mediação semiótica incida sobre a imagem subjetiva que esses alunos delineiam para a realidade objetiva ${ }^{6}$, no processo de apropriação da cultura. (com base em KOPNIN, 1978; VIGOTSKI, 2001 [1934]).

\footnotetext{
${ }^{6}$ Tomamos 'objetiva', aqui, no sentido marxista do termo, remetendo a 'objetivação', tendo presente que, em uma concepção histórico-cultural, compreende-se que ' [...] o ser humano produz uma realidade objetiva, que passa a ser portadora de características humanas, pois adquire características socioculturais, acumulando a atividade de geraçóes de seres humanos." (DUARTE, 2003, p. 25) Entendemos que os processos educativos implicam apropriação do que já foi objetivado pela cultura humana, o que remete à dialética entre apropriação e objetivação. Ainda Duarte (2003, p. 25): "Cumpre observar que a objetivação não se reduz à objetivação stricto sensu, isto é, à objetivação objetual, produto de objetos, mas também se realiza sob outras formas, como a produção da linguagem, das relações entre os homens, do conhecimento etc.
} 
Essa compreensão nos convida a pensar nas propostas de Wertsch (1985) sobre intersubjetividade no que tange às considerações do autor acerca das implicações de maior ou menor semelhança no modo como os sujeitos operam com os sentidos em seus mundos privados, o que preferimos conceber aqui como relações entre apropriação da cultura por meio da ressignificação de imagens subjetivas da realidade objetiva, processo que, reiteramos, implica a dinâmica do funcionamento interpsíquico para o funcionamento intrapsíquico. Assim considerando, torna-se relevante a dialética entre pensamento, ação e criação de sentidos, para o que atentam Newman e Holzman (2002). Logo, o enfoque não estaria no signo em si mesmo. A relevância estaria na função reguladora do signo, no signo a serviço da organização do pensamento. Maiores ou menores abreviações materializadas na dimensão verbal da interlocução, processo de que trata Wertsch (1985), demandariam, portanto, em nosso entendimento, maior atenção à natureza conflituosa que caracteriza a intersubjetividade, gerando contradições que incidiriam sobre a então zona de desenvolvimento real dos sujeitos, provocando ressignificações a partir da zona de desenvolvimento iminente.

Desse modo, similitudes na forma como os sujeitos operam com os sentidos do que é relevante na interação implicam o desenvolvimento das funções psíquicas superiores, que orientam a atividade humana, o que remete a tais imagens subjetivas da realidade objetiva, as quais se formam com a internalização dos signos pela via da apropriação da cultura, transcendendo mera reprodução, mero espelhamento da realidade concreta e demandando processos educativos intencionalmente planejados (com base em VYGOTSKY, 2015 [1931]). A partir dessa compreensão, na próxima seção, retomamos o conceito de intersubjetividade, na proposta de delineamento de um olhar que nos permita considerar as provocaçôes de Wertsch (1985) sobre a natureza complexa desse conceito, mas na busca de tomá-lo sob o enfoque dos tensionamentos e contradições que vemos nessa complexidade. 


\section{Uma proposta para conceber intersubjetividade a partir do encontro}

Em estudos que temos realizado em nossos grupos de pequisa ${ }^{7}$, vimos nomeando como intersubjetividadelintersubjetivo o que o ideário vigotskiano nomeia como interpsíquico, assim como vimos nomeando intrassubjetividadel intrassubjetivo o que aquele autor nomeia como intrapsíquico (VYGOTSKY, 2015 [1931]; VIGOTSKI, 2000 [1968]). Trata-se de um comportamento que deriva da concepção de sujeito que temos adotado em nossos estudos, fundamentada na assunção de que a subjetividade constitui-se nas relações com a alteridade, o que deriva de uma ancoragem vigotskiana na articulação que propomos com o pensamento bakhtiniano ${ }^{8}$.

Assim, buscamos estender a atenção focada prioritariamente na formação social das funções psíquicas (VYGOTSKY, 2015 [1931]) para a importância dessa formação em se tratando da constituição da subjetividade nas relações social, histórica e culturalmente situadas entre o sujeito e o(s) outro(s), nas quais tais sujeitos em interação incidem mutuamente sobre suas próprias interpretações da realidade natural e social (VOLOCHINOV ${ }^{9}, 2013$ [1930]), sobre suas imagens subjetivas da realidade objetiva (KOPNIN, 1978), sobre suas formas de apropriação da cultura (com base em VYGOTSKY, 2015 [1931]) até então. Escreve, em

\footnotetext{
${ }^{7}$ A exemplo de Cerutti-Rizzatti, Pereira e Pedralli (2013), Cerutti-Rizzatti, Daga, Catoia Dias (2014), entre outros estudos, no âmbito do grupo Cultura Escrita e Escolarização, grupo este vinculado ao Núcleo de Estudos em Linguística Aplicada.

${ }^{8}$ Estamos cientes de que M. Bakhtin fundamenta-se em uma perspectiva dialógica nos estudos da linguagem, diferentemente de L.S. Vigotski, cuja fundamentação é dialética. Compreendemos, porém, haver uma estreita articulação entre escritos de V. Volochinov, no âmbito do Círculo de Bakhtin, e de L.S. Vigotski: parece-nos que discussóes registradas na primeira parte de Marxismo e Filosofia da Linguagem - texto atribuído a V. Volochinov por boa parte dos estudiosos do Círculo - e discussões de L.S. Vigotski sobre o signo têm significativas aproximaçôes. Brandist (2012, p. 11), ainda que atente para divergências entre as bases do pensamento de L.S. Vigotski e as bases do pensamento do Círculo de Bakhtin, permite inferir que V. Volochinov e L.S.Vigotski foram coetâneos no Instituto de Línguas em Leningrado e escreve: “[...] Bakhtin, Voloshinov e Vygotsky frequentemente leram os mesmos livros, mas [...] Voloshinov e Vygotsky realizaram projetos de pesquisa coletivos em instituiçóes com objetivos compartilhados."

${ }^{9}$ Também para esse autor russo, manteremos a grafia do nome da forma como aparece traduzida na obra objeto de referenciação.
} 
uma perspectiva bakhtiniana, Faraco (2009, p. 76): "A subjetividade se constitui e se move no denso caldo do simpósio universal, sendo a alteridade e a intersubjetividade, portanto, absolutamente indispensáveis."

Esses olhares têm nos levado a tomar o sujeito como foco, sem, no entanto, descurar da atenção à dimensão psíquica da constituição subjetiva, mas - tal qual vemos no ideário vigotskiano - compreendendo essa dimensão psíquica como implicação das relaçôes sociais, daí a "formação social da mente" (VYGOTSKI, 2015 [1931]; VIGOTSKI, 2000 [1968]). Inscritas, porém, em uma abordagem mais epistemológica e filosófica do que propriamente psicológica, optamos - tal qual já registrado - por usar intersubjetivo em lugar de interpsíquico. Essa opção, no entanto, levounos ao uso de intersubjetivo e intersubjetividade, em muitos de nossos estudos $^{10}$, suscitando, não raro, mera sinonímia com interpessoal, equívoco de que temos fugido hoje com base em Wertsch (1985): para que haja intersubjetividade importa chegar-se a um estágio nas relaçóes interpessoais em que se estabeleçam efetivamente similitudes, entre os sujeitos, na forma de operar com interpretações de mundo, do que é indício a paulatina abreviação nos usos da linguagem no que se refere, por exemplo, como menciona o autor, à redução de demandas de referenciação via categorias nominais nocionais; uma maior entrada de dêiticos seria, por exemplo, um dentre os sinais de um crescente aumento dessas similitudes. Assim considerando, não nos parece mais possível conceber intersubjetivo na superfície do que se nomeia interpessoal - sem a mencionada gradação -, tanto quanto importa ter presente essa complexidade da intersubjetividade quando mencionado o plano interindividuals como vemos, por exemplo, em Geraldi, Fichtner e Benites (2006, p. 190):

Os processos de encontro e desencontro com a alteridade são constitutivos de nosso olhar, de nossa representação de nós mesmos, e, mais profundamente ainda, é nesses encontros que emerge a linguagem e a linguagem se faz linguagem interior. Ou seja, os processos de internalização do que é interindividual para intraindividual passam pela linguagem, e a linguagem emerge e está na relação com a alteridade.

Identificamos, também nesse olhar dos autores, a importância que Wertsch (1985) atribui à linguagem. Temos, porém, preterido individuall

${ }^{10}$ Dissertações de Mestrado de Mossmann (2013) e Almeida (2013) são exemplos desse uso. 
indivíduo em favor de subjetivo/sujeito respectivamente, em nome de nossa filiação ao pensamento do filósofo italiano Augusto Ponzio, que distingue indivíduo e sujeito ao propor o encontro da outra palavra com a palavra outra. Ponzio $(2010 ; 2013 ; 2014)$ concebe que esse encontro só é possível fora do que chama relaçôes funcionais, entendidas como aquelas que se prestam à lógica do mercado global; para ele, importa haver relaçôes infuncionais, que correspondem às relações de natureza afetiva e àquelas implicadas na literariedade ${ }^{11}$. Essas relações, no entendimento desse filósofo, dão-se entre sujeitos singulares e não entre individuos intercambiáveis, e nelas não há álibi para o existir humano - os sujeitos se desvestem da imobilidade e dos limites impostos por seus 'escafandros' de identidade de grupo, de gênero, de nacionalidade, de profissão e categorias afins, porque não estão a serviço da lógica do mercado (PONZIO, 2014) -, o que remete a Bakhtin (2010 [1920-24]), já que se trata de relações que se estabelecem a partir do que o autor italiano chama de diferença não indiferente, ou seja, a diferença importa porque implica singularidade; logo, não é possível intercambialidade entre indivíduos em relações que se estabelecem nos limites dos papéis sociais e identitários de que cada qual desses indivíduos comumente se reveste: o 'escafandro', a "armadilha da identidade". As relações infuncionais, ao contrário, criariam o lócus para o encontro entre sujeitos singulares, insubstituíveis porque tomados fora da sujeição a tais papéis sociais e fora de tal "armadilha da identidade" (PONZIO, 2013; 2014).

Essa é uma questão para nós especialmente cara, porque consideramos que a aprendizagem que move o desenvolvimento, no sentido vigotskiano de ambos os conceitos, demanda a intersubjetividade, decorrente da gradação de que trata Wertsch (1985), com as ressalvas anteriormente feitas à importância de se ter presente o conflito, a reação-resposta no sentido bakhtiniano do termo, que necessariamente se instaura nessa interlocução, na consolidação de tal estado de intersubjetividade. Temos compreendido, adicionalmente, que intersubjetividade, como a concebe Wertsch (1985), é passível de aproximação com o conceito de encontro do mencionado filósofo italiano, especialmente se considerarmos que o foco do autor norte-americano é a díade mãe-criança, a qual se coloca inteiramente no âmbito das relações

\footnotetext{
${ }^{11}$ Optamos por literariedade aqui e outras ocorrências, e não por literatura, porque o filósofo faz menção ao que é do plano da infuncionalidade, que foge às relaçóes de mercado; e entendemos que a literatura, em muitos contextos, rende-se a essas relaçóes.
} 
infuncionais, fora da lógica do mercado, de que trata Ponzio (2010; 2013; 2014). Assim, a condição de encontro seria requisito para a instauração de uma interlocução passível da gradação tal qual entende Wertsch (1985); esta, por sua vez, condição para a aprendizagem.

Desse modo, para as finalidades deste artigo, nossa proposta de ressignificação conceitual sintetiza-se em conceber o conceito de intersubjetividade a partir desse autor norte-americano em convergência com o conceito de encontro do mencionado filósofo italiano, compreendendo que, para haver aprendizagem - nesse caso, em se tratando de línguas -, importa que professores e estudantes engendrem um processo de paulatina similitude na forma como operam com suas interpretações de mundo (com base em VOLOCHINOV, 2013 [1930]), considerado o professor como o interlocutor mais experiente, à luz do ideário vigotskiano, mas tendo presente o conceito de refração e de reação-reposta - neste caso, dos estudantes -, conceitos que derivam do ideário bakhtiniano, isso sempre no âmbito da condição de sujeitos singulares não intercambiáveis (PONZIO, 2013; 2014) sob a qual são tidos os interactantes, compreensão que buscamos abrir na próxima seção.

\section{0 exercício da intersubjetividade no lócus do encontro}

A convergência conceitual que propomos, na seção anterior, tem emergido de nossas vivências no campo do ensino e da aprendizagem em línguas nos núcleos de estudos de que fazemos parte, no âmbito dos quais temos tornado nossas interações com nossos alunos - nesse caso, acadêmicos - momentos fecundos em busca do que vimos chamando 'exercício da intersubjetividade no lócus do encontro'. Para tal, temos transformado momentos institucionalizados de orientação de projetos de pesquisa e extensão em interessantes espaços de reflexão sistematizada sobre esse mesmo exercício.

Valendo-nos do interpretativismo (MASON, 1996) como abordagem de pesquisa e do que chamamos de diários de orientação como instrumentos de geração de dados para essa reflexão, temos nos mantido atentas à compreensão de Rockwell (2009, p. 48), para quem o olhar qualitativo implica a "[...] elaboración de los registros y del diário [...] la constante observación e interación [...] es la fuente de mucha de la información más rica y significativa [...]". Desse modo, ao longo dos últimos três anos, vimos mantendo tais registros - ora mais, ora menos sistemáticos - em 
diários, com notas numeradas e identificadas. Tais notas são feitas por nós, orientadoras, cada qual em seu próprio diário de orientação, documentando o que entendemos ser um processo de paulatina maior similitude na forma como nós e os estudantes de nossos grupos temos operado no que respeita-sob um olhar bakhtiniano - às interpretações da realidade natural e social (com base em VOLOCHINOV, 2013 [1930]) e - sob um olhar vigotskiano - à imagem subjetiva da realidade objetiva (com base em KOPNIN, 1978), isso em se tratando de nosso objeto de estudo: o ensino e aprendizagem de línguas.

Nessas vivências, temos buscado - dentre outros desdobramentos contemplados em projetos de pesquisa mais amplos - responder à seguinte questão-problema: Que relações é possivel estabelecer entre: (i) o que avaliamos como um paulatino amadurecimento no domínio teórico visivel nas enunciaçôes orais e escritas de acadêmicos sob nossa orientação e (ii) o estreitamento das relações correspondentes a essa mesma orientação institucionalizada entre nós e eles?" O filtro para a seleção das notas de campo que serão apresentadas a seguir, na busca por responder a essa questão-problema, são os conceitos de intersubjetividade e de encontro de que vimos nos ocupando neste artigo.

Importa registrar inicialmente que mantemos dois grupos de pesquisa, vinculados à ação docente de cada uma de nós, autoras deste artigo, nos departamentos universitários nos quais atuamos, grupos que convergem em razão da base histórico-cultural que aproxima nossos projetos de pesquisa. Nesses grupos, vimos convivendo, nos últimos três anos - período recortado para as finalidades deste artigo -, com cerca de trinta acadêmicos, entre graduandos bolsistas, mestrandos e doutorandos. Nossa rotina de orientação prevê - ou previu, em anos anteriores, no caso de duplas e trios - sessóes sistemáticas individuais, em duplas ou trios de trabalho no âmbito da extensão, assim como sessões sistemáticas e coletivas de estudos e discussões sobre bases teóricas que sustentam nossas ações de pesquisa e extensão. Ater-nos-emos, aqui, a um de nossos grupos de pesquisa e - por implicação a um de nossos diários de orientação, reiterando que cada uma de nós mantém o seu próprio diário-, grupo que, também para as finalidades deste artigo, nomearemos como GO - Grupo de Orientação. Constituem esse grupo, acadêmicos, quer com um maior tempo de vivência conjunta, quer recentemente integrados aos veteranos, o que tem nos facultado um olhar mais atento, sob o ideário vigostkiano, para as relaçóes entre autonomia e heteronímia no âmbito do GO. Em face da ética de pesquisa, codificaremos as menções feitas aos participantes do grupo usando iniciais em maiúsculas - 
que evocam em parte e em parte substituem seus nomes - em itálico, seguidas de ponto final, de modo a evitar superposições com eventuais abreviaturas usadas no corpo do texto. As menções correspondem ao conjunto de cerca de quinze acadêmicos, participantes do GO ao longo dos últimos três anos, e os critérios para a seleção dos dados são movimentos em que o estado de intersubjetividade parece em consolidação, não havendo nenhum outro critério adicional, a exemplo de eventual maior ou menor engajamento no grupo ou itens afins que suscitariam uma equivocada hierarquização dos estudantes por avaliação de seu desempenho, questão inteiramente oposta às bases deste estudo, como explicaremos à frente.

Tendo selecionado as notas a partir de tais critérios, mantivemos dois enfoques convergentes para a análise de tais dados selecionados fazendo-o na busca por responder à questão-problema a partir da qual se erige este artigo. O primeiro enfoque tem como diretriz analítica o movimento de consolidação do encontro dos estudantes com uma de nós na condição de orientadora - mantemos, porém, ambas as autoras, reuniōes sistemáticas entre nós duas para discussão dos dados registrados nesses diários, objetivando analisar nossos percursos de pesquisa de modo a ressignificá-los em um trabalho conjunto. $\mathrm{O}$ segundo enfoque - entendendo ter conquistado a condição de encontro - tem como diretriz analítica uma crescente maior similitude - visibilizada nas enunciações orais e escritas dos acadêmicos - das interpretações e imagens subjetivas entre orientandos e orientadora, em uma discussão acerca da consolidação de um possível estado de intersubjetividade com base nas proposições de Werstch (1985).

\subsection{Em busca da paulatina conquista da condição de encontro, lócus para a intersubjetividade}

Sob a já mencionada ótica de Ponzio $(2010 ; 2013 ; 2014)$, encontro implica a ruptura de relações entre individuos intercambiáveis e a busca pelo estabelecimento de relaçôes entre sujeitos singulares, desafiando a funcionalidade das relações de mercado em favor da infuncionalidade que caracteriza relações afetivas e literariedade; como fazer isso no plano dos propósitos acadêmicos era nosso primeiro desafio. Para dar conta dele, temos nos valido de uma proposta de ressignificação parcial desse olhar do filósofo italiano, argumentando que relações de natureza educacional, especialmente no âmbito das ciências ditas 'humanas', requerem dos envolvidos colocar em xeque a funcionalidade das relaçóes de mercado que sustentam - neste 
caso - a formação acadêmica, sobretudo quando temos uma base históricocultural como matriz teórico-epistemológica para nossa ação docente. Sob tal escrutínio, entendemos que poderia haver o encontro mesmo no plano das relações entre orientador e acadêmico, do que tratamos aqui, mas, para tanto, importa o exercício da fuga da intercambialidade típica da funcionalidade, tanto quanto a fuga dos 'escafandros' da cristalização das identidades de 'professor' e 'estudante'.

Assim, vimos nos dispondo a entabular, com nosso grupo de acadêmicos, relações em que exercitemos a condição de sujeitos singulares, para os quais as diferenças que caracterizam cada um não são indiferentes ao outro, desafiando os álibis interpostos por tais 'escafandros' e 'armadilhas' das identidades preestabelecidas e rijas (com base em PONZIO, 2014). Esse, porém, não é um exercício fácil, tanto quanto não data de agora: decorre de quase uma década para cada uma de nós autoras deste artigo, embora apenas nos últimos três anos o venhamos fazendo explicitamente a partir do conceito de encontro, com documentação em diário; daí as razões do recorte temporal já mencionado.

Os estudantes a que aludimos nesta seção têm convivido estreitamente conosco ao longo dos últimos seis anos; os dados em diário, porém, reiteramos, datam tão somente de três anos atrás, e as notas selecionadas são aquelas que indiciam o movimento de apropriação da cultura - neste caso, bases teóricas e epistemológicas com que trabalhamos. Não mencionamos, pois, notas em que registramos o que entendemos serem obstáculos, recuos, desistências, porque, embora em um bom número em nossos registros, elas fogem ao foco deste artigo. Iniciamos, assim, a discussão com a posposição as três notas de campo a seguir que evocam o olhar para a singularidade dos sujeitos.

1. Tem chamado a atenção a singularidade de NFP.; destaca-se pela disciplina e pela organização com que lida com as leituras e com a escrita de cada seção do ensaio de que se incumbiu. Uma busca de verticalização e extrapolação. A atenção e a pontualidade são destaques. Há cuidado em ouvir, cuidado que se estende para a forma e o conteúdo do que é objeto de ausculta no plano das interações entre nós. (Nota 32 - GO, 2012a).

2. A sessão de hoje reiterou o aprofundamento que SSJ. vem mostrando dia a dia em suas compreensóes teóricas. É uma solidez que se revela paulatinamente mais visivel, ao longo de nossas interaçôes, em sua fala e em sua escrita. SSJ. tem revelado destreza no que respeita à natureza 
filosófica das discussões; procede a articulaçôes entre o pensamento dos autores de modo apropriado e o faz com um olhar de introspecção muito seu, critico e atento. (Nota 122 - GO, 2012b).

3. LDW. distingue-se pelas perguntas que enuncia, sempre instigadoras. O conteúdo de grande parte de suas perguntas indicia um modo particularmente seu de refletir sobre o que vimos discutindo. Não se limita à ausculta, problematiza nossas interaçôes de uma forma inquietadora. Na problematização parece estar sua singularidade. (Nota $67-\mathrm{GO}, 2012)$.

As vivências semanais com o grupo trazem novos elementos para a depreensão das particularidades que entendemos caracterizar cada um dos acadêmicos, as diferenças deles entre si: as diferenças que não nos são indiferentes, porque nelas está sua singularidade como sujeitos, daí a impossibilidade de haver intercambialidade (PONZIO, 2013; 2014). Nossa crescente atenção a tais idiossincrasias tem nos mostrado a impossibilidade de comparaçôes entre os processos de aprendizagem e desenvolvimento no interior do grupo: cada um avança a partir dessas mesmas singularidades, implicadas no delineamento de suas zonas de desenvolvimento reale iminente (com base em VIGOTSKI, 2000 [1968]). Importa que nossa ação docente, no encontro que ali se instaura, contemple essas singularidades, compreensão da qual ecoam as notas de campo a seguir.

4. É interessante observar como, no interior do grupo, os acadêmicos se qualificam mutuamente, com alcunhas que parecem dar conta da singularidade de cada um, apontando para os predicados que veem uns nos outros, como distintivos dentre eles, o que denota a riqueza de suas diferenças e a impossibilidade de quaisquer comparaçôes entre eles; tratase da forma como cada qual se move ali, tornando-se único. Seus textos e sua atuação nos diferentes espaços em que lhes é dado se manifestarem mostra que só é possivel qualificar um ou outro desempenho como melhor a partir de um ou de outro critério bem especifico e sempre os tendo, cada qual, como seu próprio parâmetro. Esse é um movimento que temos visto nos últimos anos de modo bastante explícito. (Nota 189-GO, 2014a).

5. Do significativo desenvolvimento de PHQ. emerge o reconhecimento do que entendemos ter sido 'uma atuação que foi perfeita' no momento presente. Essa qualificação da atuação, porém, tem PHQ. como seu 
próprio parâmetro. Temos entendido que tais qualificaçôes somente são possiveis no espectro da história que cada sujeito no grupo erige gradualmente, ou seja, só pode ter o próprio sujeito de ontem como parâmetro para qualificação da atuação desse mesmo sujeito hoje. (Nota 245 - GO, 2014b).

Nesse olhar mais atento para as singularidades, porém, vemo-nos ante o desafio de fugir ao relativismo e ao subjetivismo, empenhando-nos - ao contrário disso - em ancorar nossa atuação na tensão entre o plano singular e o plano universal, cuja união, com base em Bakhtin (2010 [1920-24], p. 81), está na singularidade do ato responsável, no qual não há álibi para o existir humano:

Do interior do ato mesmo, tomado em sua integridade, não existe nada de subjetivo e de psicológico; na sua responsabilidade, o ato coloca diante de si sua própria verdade como verdade que une ambos os seus aspectos, assim como une o aspecto do universal (a validade universal) e do individual (o real). Essa verdade unitária e singular do ato é posta como tarefa enquanto verdade sintética.

Também no âmbito de uma epistemológica de base histórica e cultural, Heller (1970, p. 47) escreve: “Todo homem é, ao mesmo tempo, ente particular-individual e ente humano-genérico, ou seja, uma 'singularidade' e, simultaneamente, uma parte orgânica da humanidade, da história humana." Assim, compreendemos que a condição de encontro - a nosso ver, em si mesma condição para a intersubjetividade - exige de nós esse cuidado: ter o próprio sujeito como parâmetro de seu desenvolvimento, como quer o ideário vigotskiano; mas, por outro lado, sem perder de vista a teleologia da formação acadêmica de cujo percurso nos cabe participar: habilitar, neste grupo, cada um dos sujeitos singulares - o plano individual de que tratam Bakhtin (2010 [1920-24]) e Heller (1970) - para uma ação em pesquisa e em docência no campo do ensino e da aprendizagem de línguas - o plano universal ao qual nos remetem também esses dois autores.

Compreendemos que, nesse desafio, coloca-se a busca pela consolidação da condição de encontro, que requer de nós, ainda, destituirmo-nos de nossos álibis, dos limites que nossa identidade como 'professores' impõe na relação com os acadêmicos. 
6. Interlocuções externas têm marcado laços que nos ligam aos acadêmicos e que ligam os acadêmicos entre si, especialmente a busca por sua autonomia no sentido vigotskiano do conceito. Tais laços se estendem à forma como os estudos de uns reverberam nos estudos de outros, em referenciaçôes recíprocas, materializando o dialogismo que entendemos haver no cotidiano de suas relaçôes e deles conosco (Nota $201 \mathrm{GO}-$ 2014b).

$\mathrm{Na}$ atenção a essas questôes, persistimos no exercício por fugir da "armadilha da identidade" de que trata Ponzio (2014, p. 55):

A relação diferença-indiferença própria do macroscomo da coletividade se encontra no microcosmo da identidade individual. A comunidade egológica, a comunidade dos eus em que consiste a identidade de cada um de nós, apresenta o mesmo tipo de sociabilidade fundado sobre a recíproca indiferença [...] da recíproca separação e indiferença entre papéis, competências, atribuiçôes, linguagens [...]

Assim considerando, entendemos que tal exercício cotidiano do encontro, que nos parece mais efetivamente possível no âmbito dos grupos menores em se tratando da atividade acadêmica - como se dá no GO -, é condição para que a aprendizagem mova o desenvolvimento (com base em VIGOTSKI, 2000 [1968]), para o que, por sua vez, é condição, como mostra Wertsch (1985), alcançar o estado de intersubjetividade, de que trataremos na próxima seção.

\subsection{A intersubjetividade que tem o encontro como lócus}

Vimos propondo, ao longo deste artigo, a convergência entre o conceito de intersubjetividade a partir de Wertsch (1985) com o conceito de encontro a partir de Ponzio $(2010 ; 2013 ; 2014)$ e, nessa proposição, compreendemos que haver o encontro é implicação para se chegar ao estado de intersubjetividade - não nos parece possível a conquista desse estado quando as diferenças são indiferentes, quando há intercambialidade de indivíduos, quando se está no interior dos 'escafandros' (PONZIO, 2014). Reiteramos que o enfoque do autor norte-americano à díade mãe-bebê suscita as relações afetivas infuncionais concebidas pelo filósofo italiano como habitat para o encontro.

Desse modo, partimos, tal qual mencionamos anteriormente, da disposição de uma ruptura com a natureza funcional das relações 
acadêmicas, na busca pelo exercício do encontro, porque também na busca pela intersubjetividade. É amplamente sabido - e o reconhecemos - que as relações acadêmicas têm como fito a formação de profissionais e, por decorrência, estão afetas às relaçôes de mercado. É nosso entendimento, porém, que formar educadores sob uma base histórico-cultural requer de nós outra dimensão para além dessa funcionalidade mercadológica, o que exige, por extensão, que entabulemos relações de outra ordem com aqueles que formamos - questão da qual nos ocupamos na subseção imediatamente anterior.

Habilitar educadores sob essa perspectiva exige que haja apropriação de conhecimentos, aprendizagem que mova o desenvolvimento (com base em VIGOTSKI, 2000 [1968]), o que implica intrassubjetividade. Para que isso aconteça, segundo mencionamos com base em Wertsch (1985), requerem-se similitudes crescentemente mais efetivas entre a forma como os interactantes operam com os objetos culturais postos na interlocução, de modo a se chegar a tal estado de intersubjetividade, do qual emerja apropriação de conhecimentos em uma nova zona de desenvolvimento real, facultando ao sujeito - neste caso, os acadêmicos - autonomia em lugar da heteronomia em relação à nossa ação docente.

Os registros de que vimos nos ocupando no mencionado grupo de pesquisa nos últimos três anos apontam para processos marcadamente caracterizados por este movimento aqui descrito: sujeitos que, inicialmente, não operam com interpretações para o mundo natural e social (VOLOCHINOV, 2013 [1930]), ou com imagens subjetivas para a realidade objetiva (KOPNIN, 1978) semelhantes às nossas, naquilo que entendemos por lingua e, mais especificamente, por ensino de línguas, compreensões ancoradas no domínio das teorias com que lidamos. À medida, porém, que a condição e encontro se consubstancia, dá-se a gradação das relações interpessoais e uma paulatina apropriação de conhecimentos e, quando entendemos chegar ao estado de intersubjetividade, compreendemos poder vivenciar efetivamente a autonomia dos sujeitos, quando eles prescindem de nossas intervenções, de nossos reparos, de nossos acréscimos, de nossos apêndices: vemos delineado um novo estágio de desenvolvimento a partir do percurso da aprendizagem (com base em VIGOTSKI, 2000 [1968]). É certo que se trata de um movimento muito distinto de uns para outros dentre esses sujeitos, tanto no que se refere ao tempo demandado para fazê-lo, como no que se refere ao modo como essa apropriação se dá no 
delineamento da autonomia no domínio teórico. Tentamos traduzir essas vivências, sinteticamente, em notas de campo que seguem, tomadas como indícios pontuais desse movimento.

7. Merece menção a forma como CCV. enunciou-se oralmente na situação em questão hoje. Não parece o mesmo sujeito de um ano atrás: a senhoria em relação ao conteúdo tematizado dispensou que olhasse para nós, como de hábito, em busca de aprovação ou de correção; referencia os autores com menção precisa às obras, fazendo-o com autonomia e adequação conceitual. Há cerca de ano e meio, CCV. demandava que endossássemos cada frase sua, como que em um referendum. Agora, passado esse tempo de interlocução entre nós e de CCV. com o grupo, o que se vê é uma senhoria conquistada a cada novo mês. (Nota de campo $99-\mathrm{GO}, 2013 \mathrm{a})$.

8. Têm sido visiveis as mudanças que se operam na escrita de OLZ. Das primeiras seçôes do projeto que lhe cabe escrever até o texto atual, as mudanças são evidentes. O ensaio teórico agora tem maior profundidade, maior adequação; a urdidura entre os autores é feita a partir de uma perspectiva critica mais madura. As entradas de propostas de ajustes que normalmente fazemos têm diminuido substancialmente. Em alguns trechos, são evidentes revozeamentos nossos e do grupo; não se trata, porém, de nenhum tipo de transcrição ou de assimilação: vế-se refração, no que entendemos ser um processo de apropriação conceitual. (Nota de campo 157 - GO, 2013b).

9. A última versão do capitulo escrito por WYF em nada lembra a primeira - esta é a quinta versão, mais aprofundada e mais consistente; há incorporação de muito do que dissemos, mas é uma incorporação que sinaliza para um processo de reflexão a partir de nossa interlocução. WYF. não parece o mesmo sujeito de um ano atrás, quando revelava insegurança, pouca confiança no potencial que víamos em suas açôes. (Nota de campo 78 - GO, 2013a).

Tais notas ilustram - no plano abreviado requerido por um artigo acadêmico - o movimento paulatino, que temos vivenciado neste grupo, de similitudes crescentes na forma de operar com interpretações para a realidade natural e social, o que se mostra também, como sinaliza Wertsch (1985), para maiores entradas de dêiticos na interlocução, para uma enunciação crescentemente mais econômica, para referenciaçôes que, aos poucos, deixam de demandar explicações longas e pontuais nossas. 
Nossos grifos em (8) e (9) remetem, ainda, à forma com que o ideário vigostkiano concebe a imitação, como um mecanismo para a internalização, implicando necessariamente a transformação. A imitação não é circunscrita à repetição, o que não cerceia o aprendiz. Evidencia-se como uma forma de 'absorção' do que é do outro, conferindo-lhe, no entanto, peculiaridades e valores idiossincráticos (com base em BALDWIN, 1895; VALSINER; VAN DER VEER, 2000; LANTOLF; THORNE 2006). No campo do estudo dos conceitos, a imitação é constitutiva da dialética entre conceitos cotidianos e conceitos cientificos (com base em VIGOTSKI, 2001 [1934]), tomando-a não como causa, mas como constitutiva do processo de aprendizagem, integradora do movimento dialético entre conceitos cotidianos e conceitos científicos (com base em VIGOTSKI, 2001 [1934])

Em se tratando da intersubjetividade, porém, entendemos que o conflito, a resistência, a refração, os recuos são parte do processo de tornar intrapsicológico o que é interpsicológico, e entendemos que aí está a nossa possibilidade de aprendizagem, como professores. Ponzio (2010), ao tratar do encontro da outra palavra com a palavra outra, remete a tensionamentos entre Babel e Pentecostes, o que, reiteramos, não tomamos pelo veio de um eventual relativismo - ponto extremo que o próprio filósofo italiano nega, por entender tratar-se de olhar tão equivocado quanto o dogmatismo -, mas na já mencionada tensão entre o singular e o universal (HELLER, 1970). Desse modo, como apontam os críticos de Wertsch (1985), o percurso da dimensão interpsicológica para a intrapsicológica é permeado pelo conflito, pela resistência, pela tensão. As notas que seguem sinalizam para tal:

10. DSG. instiga-nos, nos faz invariavelmente pensar sobre outras possibilidades para o que estamos dizendo, e seus argumentos tendem a ser sempre consistentes. Não se trata, porém, de contraposiçôes; percebemos que são inquietaçôes suas, que fazem com que nos interpele e nos faça pensar sobre o que entendiamos estabilizado. O resultado tende a ser crescimento de DSG. tanto quanto nosso. DSG. tem nos mostrado possibilidades de repensarmos nossos eventuais 'assossegamentos' teóricos. (Nota de campo 54-GO, 2012b).

11. HJU. e outros membros do grupo colocaram uma questão importante sobre o tema em discussão acerca da qual não havíamos ainda refletido. Após discussão, entendemos que o caminho que vínhamos trilhando é aquele que devemos seguir, mas as interpelações de HJU. demandarão novos estudos, novas formas de ver o objeto de pesquisa. (Nota de campo 88 - GO, 2013a). 
12. Ouvimos, nestas últimas semanas, impressöes de colegas externos acerca do modo como vimos ampliando nossas bases referenciais teóricas, as buscas de articulações que temos levado a termo, na atenção ao enfoque histórico e cultural. Trata-se de um movimento resultante de tensões que emergem nas questôes, nas contraposiçôes, nas inquietaçôes dos acadêmicos e que nos fazem pensar outros modos de ver os caminhos que vimos trilhando e que, boa parte das vezes, geram um estado de insegurança nosso que demora a se dissipar de modo a dar lugar a novas âncoras sempre provisórias. (Nota de campo 267 - GO, 2015a).

Temos compreendido, paulatinamente de forma mais clara, o modo com que um grupo de estudo, pesquisa e extensão se constitui como tal, as demandas que se estabelecem para que a aprendizagem mova o desenvolvimento nas relações intersubjetivas que têm lugar no lócus do encontro (com base em VIGOTSKI, 2000 [1968]; WERTSCH, 1985; PONZIO, 2013). E, como coloca o autor norte-americano, temos estado a cada dia mais seguras de que se trata efetivamente de um movimento de gradação, de crescente maior similitude nos modos de conceber a realidade e operar com ela; neste caso, o ensino e a aprendizagem de línguas. Nesse percurso, porém - o que Wertsch (1985) parece não tematizar - há tensões, resistências, conflitos e confrontos, que desestabilizam não apenas nossos aprendizes, mas o fazem também conosco, interlocutores mais experientes que ocupam a posição de 'orientação', mas que buscam fugir do 'escafandro'.

Esse encontro vê na diferença a efetiva riqueza; ali parece se dar a mudança, a apropriação da cultura, a ponto de, após um período significativo de interlocução - sem álibis para existir (com base em BAKHTIN, 2010 [1920-24]; PONZIO, 2010; 2013; 2014) -, a autonomia emergir e vermos, nos acadêmicos, revozeamentos nossos, sim, mas revozeamentos com ressignificações, com acréscimos, com tons singulares, do que já tratamos a partir dos grifos em (8) e (9). Não raro, eles fazem deles palavras nossas, evocando a já menciona imitação, como a concebe o ideário vigotskiao, tanto quanto a bivocalidade de que trata o ideário bakhtiniano, o que transcende a abreviação do discurso mencionada por Wertsch (1985), para sinalizar um movimento, a nosso ver, ainda mais interessante: uma apropriação sua do que era nosso, mas com o seu tom, o seu acento (com base em BAKHTIN, 2003 [1979]), o seu olhar problematizador, porque com a sua história e a partir dos tensionamentos, da refração (com base em VOLÓSHINOV, 2009 [1929]) que a sua singularidade exige que sejam apresentados ao nosso dito. 
13. Hoje nos vimos diante de um quadro interessante: VBZ. fala-nos sobre uma 'lista' que vem fazendo e que conteria termos, expressóes e itens afins tidos por nós como impróprios para uso na escrita de nossos ensaios. Diz que, tendo estado afastada por um tempo das últimas discussóes do grupo por conta de novas possibilidades de trabalho, percebeu, ao voltar, maior precisão lexical nossa em relação à tradução de determinados conceitos axiais nas teorias com que operamos e tem compreendido que determinadas expressōes vêm sendo preteridas em nome de outras, as quais vinha anotando com cuidado na mencionada 'lista'. A lista contemplava expressões tidas como 'recomendadas', muitas das quais não nos tinham como origem; a origem delas estava em modos de dizer de outros membros do grupo. (Nota de campo 36 - GO, 2012a).

Assim, quando vemos esse movimento - do qual essa materialidade linguística é apenas um indicador de questões mais complexas, como sugerem os críticos de Wertsch (1985) -, estamos seguros de que a autonomia de que trata o ideário vigotskiano se consubstancia na ausculta à alteridade e na reação-resposta a ela, processo no qual temos um profissional formandose em sua singularidade, na tensão entre a sua história pessoal e o genérico humano (com base em HELLER, 1970); e, assim, compreendemos que o que é interpsicológico torna-se paulatinamente intrapsicológico para nossos aprendizes, mas com novos contornos também para nós, porque ninguém saiu ileso do encontro (com base em PONZIO, 2010).

\section{Considerações finais}

Ao final desta reflexão e na busca de sintetizar a resposta à questãoproblema que moveu o recorte feito para este artigo, qual seja: Que relaçôes é possivel estabelecer entre: (i) o que avaliamos como um paulatino amadurecimento no dominio teórico visivel nas enunciaçôes orais e escritas de acadêmicos sob nossa orientação e (ii) o estreitamento das relaçôes correspondentes a essa mesma orientação institucionalizada entre nós e eles?", entendemos que a resposta seria: trata-se de relações de intersubjetividade, as quais têm o encontro como lócus. O 'amadurecimento' que tematizamos na questãoproblema corresponderia a uma maior similitude entre a forma como operamos com as teorias com as quais trabalhamos e a forma como os acadêmicos em interlocução conosco passam a fazê-lo, percurso que seria possível tão somente a partir da intersubjetividade na gradação de que trata Wertsch (1985). Esse movimento, no entanto - como mostram Bezerra e 
Meira (2006) - não decorreria da internalização de nosso ponto de vista como orientadores; a similitude resultaria, como entendem Newman e Holzman (2002), de conexões entre pensamento, ação e delineamento de sentidos, as quais se consolidam no encontro, do modo sob o qual o concebe Ponzio $(2010 ; 2013 ; 2014)$ e que ousamos estender a relaçôes acadêmicas como as que abordamos neste estudo.

Assim, a busca por responder a essa questão-problema reitera nossa compreensão de que a formação de profissionais no campo da educação em linguagem implica o ato responsável, no sentido bakhtiniano do conceito; não são possíveis álibis que limitem nossas ações como orientadoras, tomando nossos acadêmicos como intercambiáveis. Educá-los para uma atuação nesse campo requer exatamente esta base de formação: lidar com a singularidade na tensão com a teleologia dos processos educacionais, sem o que a atenção às zonas de desenvolvimento de seus futuros alunos colocar-se-ia como mero teoreticismo (com base em BAKHTIN, 2010 [1920-24]). Eis, aqui, implicadas questões epistemológicas que transcendem questôes meramente discursivas, porque a linguagem não tem foco em si mesma; é, na verdade, instrumento psicológico de mediação simbólica (VIGOTSKI, 2000 [1968]) para que o estado de intersubjetividade seja possível.

\section{Referências}

ALMEIDA, Kamila Caetano. Sobre vozes e tensões: implicações das práticas de letramento em relações intersubjetivas na esfera jurídica. Dissertação (Mestrado em Linguística) - Universidade Federal de Santa Catarina, Florianópolis, 2014.

BAKHTIN, M. Para uma filosofia do ato responsável. São Carlos: Pedro \& João Editores, 2010 [1920/24].

BAKHTIN, M. Estética da criação verbal. 4a ed. São Paulo: Martins Fontes, 2003 [1979].

BEZERRA, Paulo. Prólogo do tradutor. VIGOTSKI, Lev S. A construção do pensamento e da linguagem. São Paulo: Martins Fontes, 2001 [1934].

BEZERRA, Henrique; MEIRA, Luciano. Zona de desenvolvimento proximal: interface com os processos de intersubjetivação. In: MEIRA, Luciano L; SPINILLO, Alina G. (Orgs.) Psicologia cognitiva: cultura, desenvolvimento e aprendizagem. Recife: Editora da UFPE, p. 190-221, 2006.

BRANDIST, Craig. Repensando o Círculo de Bakhtin. São Paulo: Contexto, 2012. 
CERUTTI-RIZZATTI, Mary Elizabeth; PEDRALLI, Rosângela; PEREIRA, Hellen Melo. Práticas de letramento: um estudo sobre conflitos e encontros na escola. Revista do GEL, São Paulo, v. 10, n. 1, p. 35-64, 2013.

CERUTTI-RIZZATTI, Mary Elizabeth; DAGA, Aline Cassol; CATOIA DIAS, Sabatha. Intersubjetividade e intrassubjetividade no ato de ler: a formação de leitores na Educação Básica. Unisinos, Calidoscópio, v. 12, n. 2, 2014.

DUARTE, Newton. Vigotski e o aprender a aprender. $3^{\mathrm{a}}$ ed. Campinas/SP: Autores Associados, 2001.

DUARTE, Newton. Sociedade do conhecimento ou sociedade das ilusôes? Campinas/ SP: Autores Associados, 2003.

FARACO, Carlos Alberto. Linguagem e diálogo: as ideias linguísticas do Círculo de Bakhtin. São Paulo: Parábola Editorial, 2009.

GERALDI, J.W.; BENITES, M.; FICHTNER, B. Transgressöes convergentes: Vigotski, Bahktin, Bateson. Campinas: Companhia das Letras, 2006.

HELLER, Agnes. O quotidiano e a história. Rio de Janeiro: Paz e TERRA, 1970.

KOPNIN, P. V. A dialética como lógica e teoria do conhecimento. Rio de Janeiro: Civilização Brasileira, 1978.

LANTOLF, James; THORNE, Steven. Sociocultural Theory and the Genesis of Second Language Development. New York: Oxford University Press, 2006.

MARTINS, Ligia Márcia. O desenvolvimento do psiquismo e a educação escolar: contribuições à luz da psicologia histórico-cultural e da pedagogia histórico-crítica. Tese de Livre Docência pela Universidade Estadual Paulista. Bauru/SP, 2011

MASON, J. Qualitative researching. London: SAGE Publications, 1996.

MOSSMANN, Suziane. (2014) $O$ ato de dizer entre Babel e Pentecostes: um estudo sobre os usos sociais da escrita na esfera acadêmica. Dissertação (Mestrado em Linguística) - Programa de Pós-Graduação em Linguística, Universidade Federal de Santa Catarina, Florianópolis, 2014.

NEWMAN, Fred; HOLZMAN, Lois. Lev Vygotsky: cientista revolucionário. São Paulo: Loyola, 2002.

PONZIO, Augusto. Procurando uma palavra outra. São Carlos: Pedro e João Editores, 2010.

PONZIO, Augusto. Fuori luogo. Milano: Mimesis, 2013.

PONZIO, Augusto. Identidade e mercado de trabalho: dois dispositivos de uma mesma armadilha mortal. In: MIOTELLO, Vladimir; MOURA, Maria Isabel. $A$ alteridade como lugar da incompletude. São Carlos/SP: Pedro e João Editores, p. 49-95, 2014. 
PRESTES, Z. R. Quando não é quase a mesma coisa: uma análise de traduções de Lev Semionovitch Vigotski no Brasil - repercussões no campo educacional. Tese (Doutorado em Educação) - Faculdade de Educação, Universidade de Brasília, Brasília, 2010.

SMOLKA, Ana Luiza B.; PINO, A. ; GOES, M. C. R. . A constituição do sujeito: uma questão recorrente. In: WERTSCH, J.; DEL RIO, P.; ALVAREZ, A. (Orgs.). Estudos socioculturais da mente. Porto Alegre, RS: Artes Médicas, v. 1, p. 143-160, 1998.

VIGOTSKI, Lev Semenovich. A formação social da mente. São Paulo: Martins Fontes, 2007 [1968].

VIGOTSKI, Lev Semenovich. A construção do pensamento e da linguagem. São Paulo: Martins Fontes, 2001 [1934].

VYGOTSKI, Lev. Semenovich. Historia del desarrollo de las funciones psíquicas superiores. In: VYGOTSKI, Lev Semenovich. Obras escogidas. Tomo III. Madri: Visor, 2015 [1931].

VOLÓSHINOV, Valentin Nikoláievich. El Marxismo y la filosofía del lenguaje. Buenos Aires: Ediciones Godot, 2009 [1929].

VOLOCHÍNOV, Valentin. Que é linguagem? In: VOLOCHÍNOV, Valentin. $A$ construção da enunciação e outros ensaios. São Carlos/SP: Pedro e João Editores, p. 131-156.,2013 [1930].

WERTSCH, James. Mind as action. New York: Oxford University Press, 1998.

Data de submissão: 18/05/15. Data de aprovação: 05/08/15. 